\title{
Retrato de Manuel Constâncio
}

\author{
Portrait of Manuel Constâncio
}

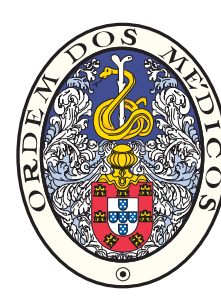

Victor OLIVEIRA 1

Acta Med Port 2013 Sep-Oct;26(5):623-625

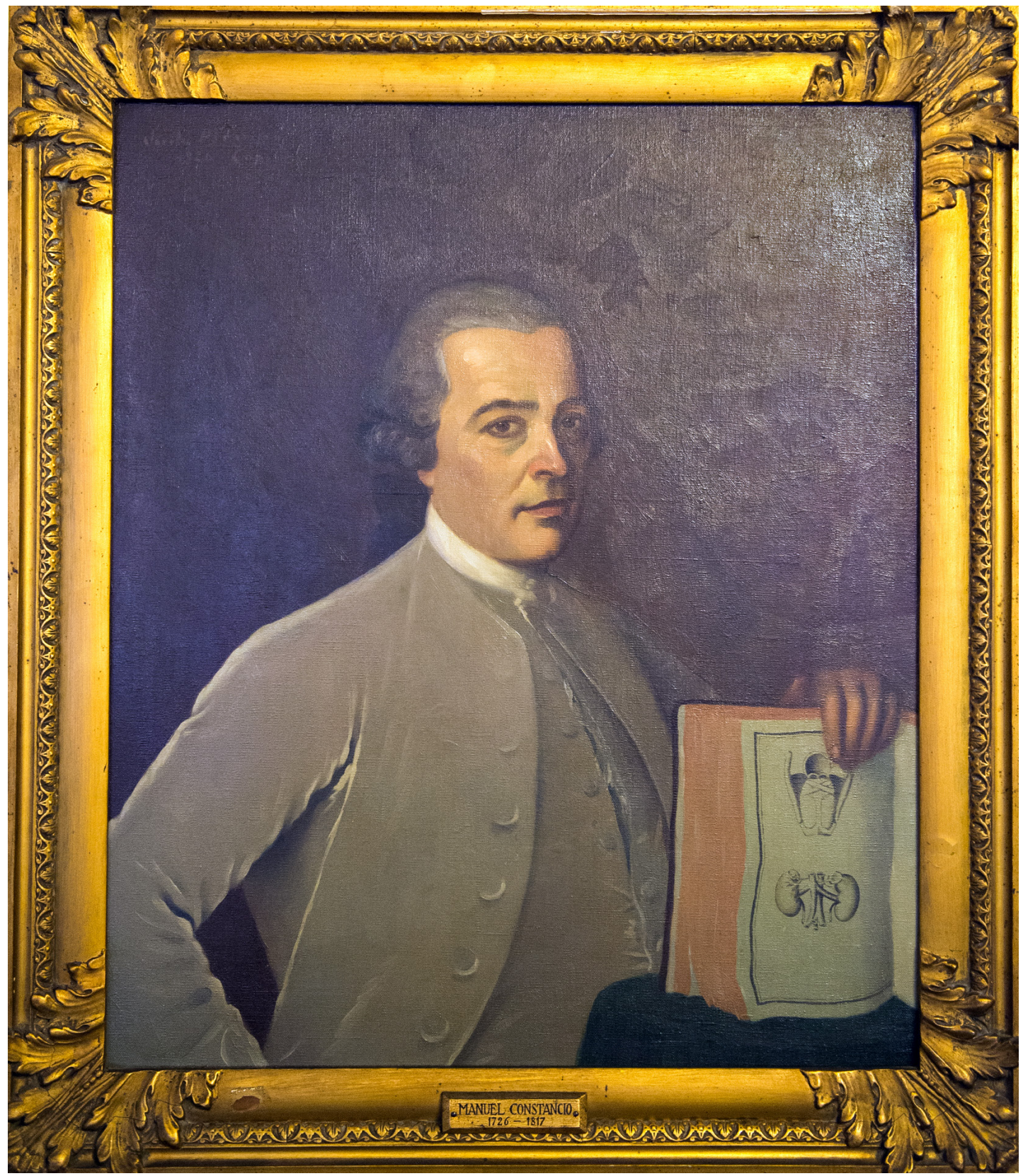

Figura 1 - "Retrato de Manuel Constâncio", Varela Aldemira, 1925. Óleo sobre tela, 90 x 80 cm. Faculdade de Medicina de Lisboa. Lisboa. Portugal. Fotografia de Luciano Reis.

Palavras-chave: Cirurgia/ história; História da Medicina do Século XVIII; Portugal.

Keywords: General Surgery/history; History of Medicine; History, 18th Century; Portugal.

1. Professor Auxiliar de Neurologia. Cadeira de Neurologia e Núcleo Histórico-Documental. Faculdade de Medicina da Universidade de Lisboa. Lisboa. Portugal.

Recebido: 23 de Outubro de 2013 - Aceite: 23 de Outubro de 2013 | Copyright @ Ordem dos Médicos 2013 


\section{O Retrato}

$\mathrm{Na}$ Faculdade de Medicina de Lisboa encontra-se um retrato de Manuel Constâncio envergando o traje de cirurgião da Real Câmara segurando com a mão esquerda, na vertical, um livro aberto em que se distinguem desenhos anatómicos (Fig. 1).

Trata-se de uma cópia em óleo sobre tela, $(90 \times 80 \mathrm{~cm})$ executada em 1925 por Varela Aldemira, a partir do original que na altura se encontrava na Quinta do Vale da Lousa.

O referido original, de data desconhecida e cuja autoria é atribuída sob reserva a Manuel da Costa $^{1}$ pois não é visível a assinatura, encontra-se actualmente na posse de um herdeiro, dado que a quinta foi, entretanto, vendida.

Nessa mesma quinta, encontra-se agora uma outra cópia executada na primeira década deste século, que substitui o original,

A importância de Manuel Constâncio, primeiro professor de anatomia português e também fundador da anatomia portuguesa, é merecedora de um reconhecimento que infelizmente se não verifica. A recordá-lo apenas existe, no seu distrito natal, o Hospital Manuel Constâncio em Abrantes, bem como arruamentos com o seu nome.

\section{O Pai da Anatomia Portuguesa}

Manuel Constâncio nasceu em 4 de Abril de 1726 na aldeia de Sentieiras, Sardoal, Concelho de Abrantes.

De origem humilde, subiu na vida a pulso: órfão aos 12 anos com mais 6 irmãos de um pequeno agricultor, iniciou-se, por necessidade de angariar sustento, como ajudante de barbeiro no Sardoal e, acompanhando o seu mestre, passou a ajudante de sangrador em Abrantes. ${ }^{2}$

As suas capacidades intelectuais e vontade de aprender, (terá mesmo começado a aprender latim), chegaram ao conhecimento do Marquês de Abrantes que o trouxe para Lisboa e o entregou ao cuidado de seu cunhado o $2^{\circ}$ Marquês de Portimão, D. Pedro de Lencastre. ${ }^{3}$
Em casa deste, serviu como criado mas de estatuto especial, pois era-lhe permitido frequentar o Hospital de Todos-os-Santos, onde se inscreveu em 27 de Fevereiro de 1750. Obteve a carta de sangrador a 16 de Julho de 1754 e passou a praticante de cirurgia do licenciado José Elias da Fonseca.

Em 21 de Outubro de 1758 terminou os seus estudos, obtendo a carta de cirurgião. ${ }^{3}$

Neste hospital, muito afectado pelo terramoto mas ainda assim a funcionar, manteve-se discípulo dilecto do professor de Anatomia de nacionalidade francesa, Pierre Dufau (1717-1806), trazido de Viena pelo Marquês de Pombal, com vista à restauração do ensino da anatomia. ${ }^{4}$

Quando Dufau se jubilou, recomendou que o seu lugar fosse entregue a Manuel Constâncio (1764) o que aconteceu a 24 de Novembro de $1765 .{ }^{2}$

Manuel Constâncio tornou-se assim o primeiro professor português a ocupar a Cadeira de Anatomia, sucedendo aos estrangeiros Monravá, Santucci e Dufau. ${ }^{5}$

Manuel Constâncio servira entretanto como cirurgião-ajudante no exército comandado pelo Marquês de Marialva, aquando das tentativas de invasão de Trás-os-Montes pelas tropas espanholas e francesas na Guerra dos Sete Anos (1762), tendo-se relacionado com John Hunter - que ocupava funções semelhantes no exército inglês que acorrera em ajuda das tropas portuguesas. ${ }^{6}$

Pela sua reputação clínica, foi nomeado cirurgião da Casa Real (alvará de 26 de Janeiro de 1786) e, pouco depois, cirurgião da Real Câmara. Recebeu ainda o título de escudeiro e cavaleiro fidalgo (28 de Agosto de 1789).

Com a influência que granjeou, conseguiu que vários dos seus discípulos fossem estudar para o estrangeiro (Londres, Edimburgo e Copenhaga) procedimento incomum até então, tendo mesmo apoiado monetariamente alguns deles. ${ }^{\top}$

De notar que alguns dos seus discípulos viriam a es-

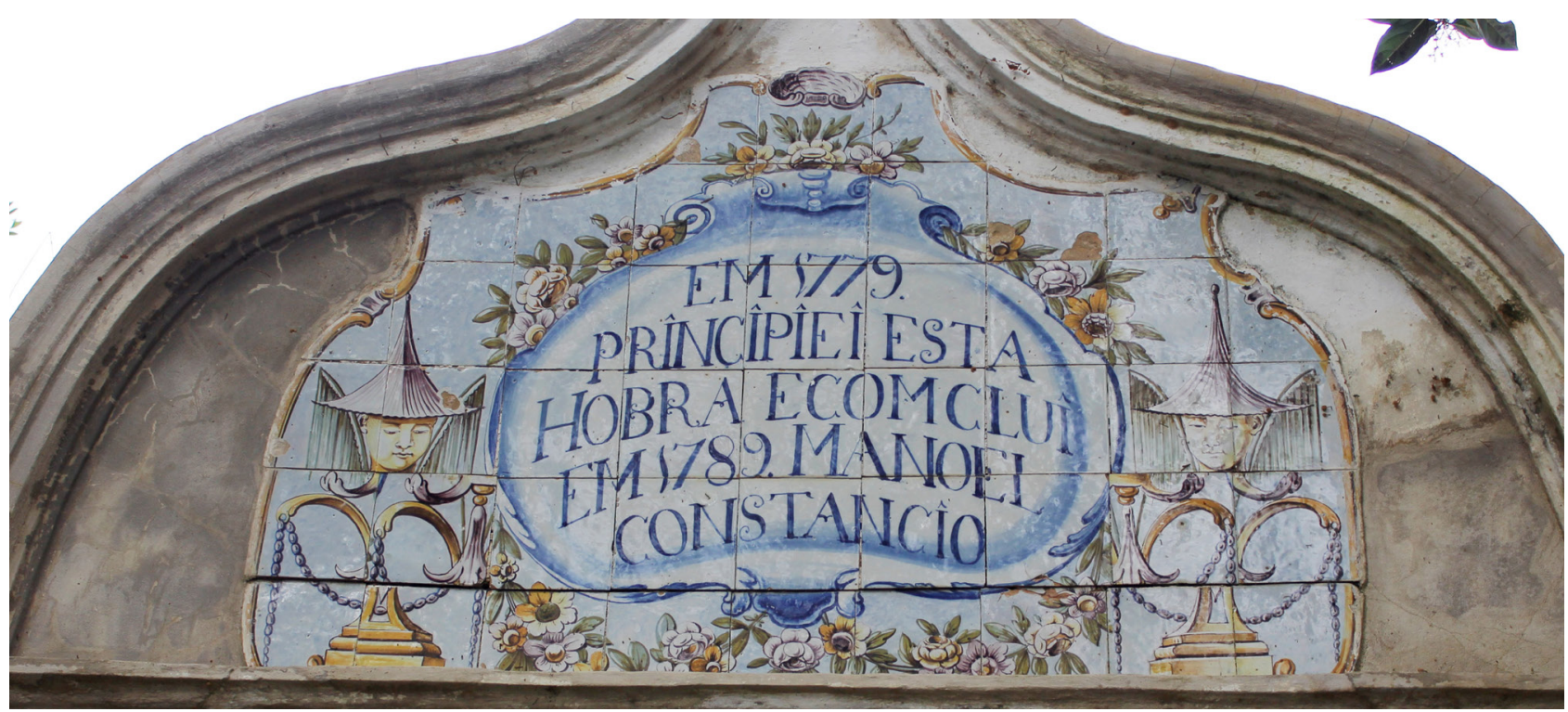

Figura 2 - Frontão da fonte principal do sistema de irrigação da "Quinta do Valle da Louza”, Sentieiras, onde se lê: 'Em 1779 principiei esta hobra e concluí em 1789. Manoel Constâncio'. Fotografia do autor. 
palhar-se pelo mundo, replicando os ensinamentos recebidos. Recordemos que em 1807 a Família Real partiu para o Brasil levando consigo os melhores cirurgiões, entre os quais se encontravam, naturalmente, discípulos de Manuel Constâncio. Assim se fundaram as escolas de cirurgia e anatomia de S. Salvador da Baía e do Rio de Janeiro. ${ }^{7}$

Em Portugal, discípulos seus estiveram na origem da Real Escola de Cirurgia que deu origem à Escola Médico-Cirúrgica de Lisboa. ${ }^{4}$

Manuel Alves de seu nome, a que acrescentou "Constâncio" introduziu a rotina de se autopsiarem os doentes falecidos nas enfermarias, dando um salto significativo na preparação dos novos cirurgiões, já que, até então, a prática das dissecções anatómicas era subestimada pelos alunos e vista com cepticismo ou mesmo hostilidade pelos poderes quer secular quer (e, sobretudo) temporal.

Era sua convicção não ser possível ser bom cirurgião sem conhecer anatomia. Bateu-se ainda para que os textos de ensino deixassem de ser escritos em latim e passassem a português, de modo a serem acessíveis a todos os praticantes.

Filho dedicado da sua terra natal, aproveitava todo o tempo livre para rumar a Sentieiras, onde construiu de raiz a "Quinta do Valle da Louza", que reproduzia, à sua escala, o fausto a que assistira na capital na época dinâmica de reconstrução após o terramoto de 1755.

Edificou assim uma casa senhorial de cariz rural com adega e capela. Os largos espaços que arborizou recriavam o ambiente aristocrático ao gosto do século XVIII. Desenhou caminhos e jardins, onde construiu um sistema engenhoso de minas para recolha de águas que iam alimentar diversas fontes e lagos. Nestes trabalhos consumiu dez anos (1779-1789) como se pode ler no frontão da fonte principal (Fig. 2).

Conquistada a aposentação a 24 de Maio de 1805, recolheu à quinta. Aí residiu até à sua morte, aos 91 anos (14 de Julho de 1817), tendo sido sepultado na capela de sua casa.

Manuel Constâncio não deixou obra publicada. São referidos apenas excertos esparsos de um manuscrito: 'Postilhas de Anatomia'. ${ }^{8}$

Outro manuscrito existe, colhido por um seu discípulo dedicado, de nome António Espírito Santo, em cujo frontispício se pode ler: 'Anatomia, a mais correcta, colhida de vários autores, os mais peritos que desta ciência têm descrevido, até ao presente, agora novamente corrigida e aumentada, assim no prático como no teórico, segundo as

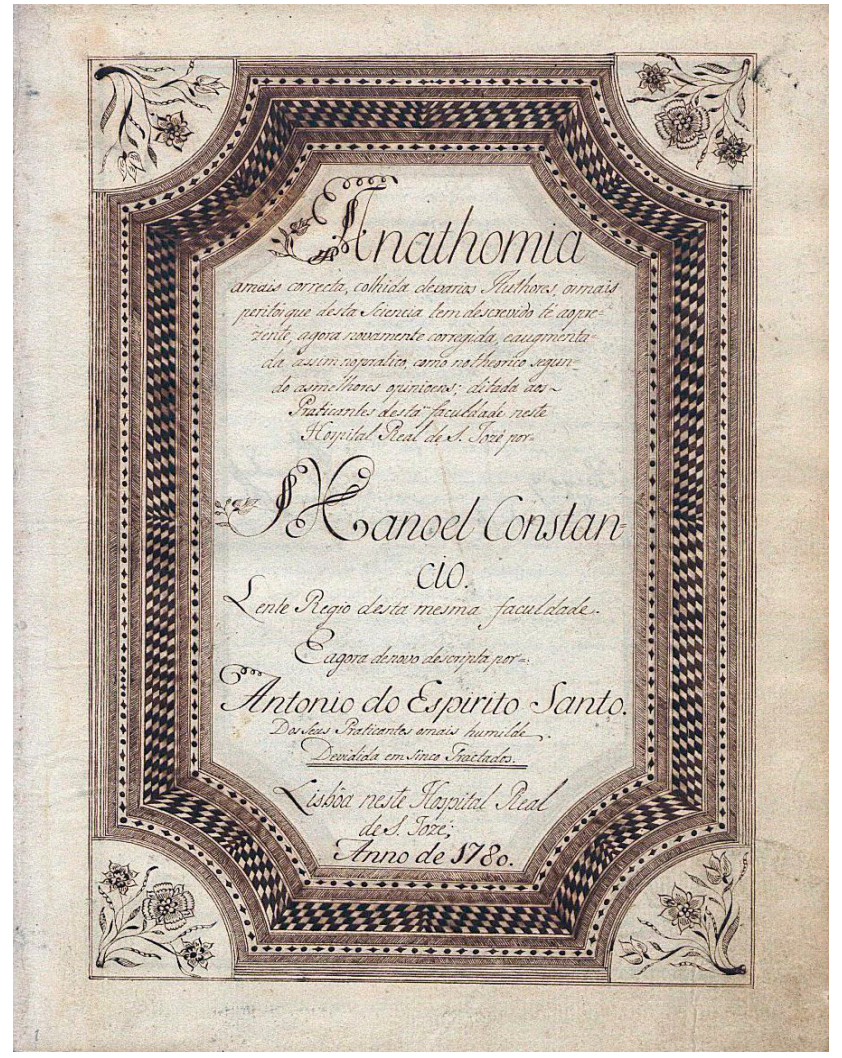

Figura 3 - "Anatomia a mais correcta", António Espírito Santo. Ano de 1780.

melhores opiniões, ditada aos praticantes desta Faculdade neste Hospital Real de S. José - Por Manuel Constâncio, lente régio desta mesma faculdade e agora de novo descrita por António do Espírito Santo, dos seus praticantes o mais humilde, dividida em cinco tratados. Lisboa neste Hospital Real de S. José. Ano de 1780'. ${ }^{9}$

Esta obra encontra-se depositada na Biblioteca da Faculdade de Medicina de Lisboa, tendo sido digitalizada, pelo que se encontra acessível por via electrónica (Fig. 3).

\section{AGRADECIMENTOS}

A Mena Martins, detentor do quadro original.

Aos actuais proprietários da quinta do Vale da Lousa por nos franquearem o acesso.

A Acta Médica Portuguesa e a Ordem dos Médicos agradecem à Faculdade de Medicina de Lisboa a gentil cedência dos direitos de reprodução deste quadro e a oportunidade de o divulgar.

\section{REFERÊNCIAS}

1. Damas Mora L. O Doutor Manuel Constâncio (1726-1817) e a Reestruturação de ensino cirúrgico em Portugal. Cirurgia. 2009;8:87-94.

2. Barbosa Sueiro M. Manuel Constâncio, a sua vida e a sua obra. Lisboa: Faculdade de Medicina de Lisboa; 1925

3. Varzeano J. Manuel Constâncio. Correio do Ribatejo. 2008;6.6.

4. Caria-Mendes J. Manuel Alves Constâncio. In: Enciclopédia Luso-Brasileira de Cultura Vol. 5. Lisboa: Editorial Verbo; 1967. p.1478-9.

5. Frada J. Os doze medalhões da Faculdade de Medicina de Lisboa. Cadernos da FML. 1996;2.

6. Colaço A. História do ensino da medicina operatória em Lisboa. Lisboa: Faculdade de Medicina de Lisboa;1925.

7. Silva Carvalho. História da Medicina Portuguesa. Lisboa: INCM; 1929.

8. Lemos M. História da Medicina em Portugal. Lisboa: sn;1899.

9. Espírito Santo A. Anatomia a mais correcta por Manuel Constâncio (1780). [Consultado em Outubro 20, 2013]. Disponível em: http:// coleccoes-digitalizadas.fm.ul.pt/repo/ULFM-res-2647/ULFM-res-2647 item $2 /$ index.html. 